\title{
PEMBERIAN TERAPI CERMIN DALAM PENURUNAN INTENSITAS NYERI PADA IBU INPARTU KALA II
}

\author{
Nicky Danur Jayanti \\ N1cky_dj@yahoo.co.id
}

\section{Prodi Kebidanan STIKES Widyagama Husada}

\begin{abstract}
In this era a lot about the world of medical research scientist with mirror therapy. This therapy can be used as a way to reduce the pain, as if the brain can predict patient back to health and recovery from illness. While in the case of childbirth mirror therapy was able to show the real state of the baby's position visually in women who are doing labor that affect the growth of maternal motivation in making an effort to push aside the pain. Measurements conducted on 20 mothers pain when the second stage, when the mother was taught to push 5 times the mother is not able to properly push past the pain scale assessment after mirror therapy treatment is done with mirrors placed with the length and width of $10 \mathrm{~cm}$. After that led her to see the state of the baby until the mother found the concentration point and will reach very high concentrations and the mother's mind is influenced by the image of the mirror so she has a very strong suggestion. Results before the mirror therapy is given is 18 respondents (90\%) with severe pain, whereas pain was only 2 respondents (10\%). Having given moderate pain mirror therapy there were 16 respondents $(20 \%)$, whereas severe pain a 4 respondents (20\%). The data obtained were statistically analyzed by paired t test T-test using SPSS. Mirror therapy proven to be effective in reducing labor pain on stage II.
\end{abstract}

Keywords: Mirror, pain intensity, labor 
ABSTRAK

Pada era sekarang ini banyak penelitian ilmuwan tentang dunia medis dengan terapi cermin. Terapi ini dapat digunakan sebagai cara untuk mengurangi rasa sakit, seolah-olah otak pasien dapat memperkirakan kembali sehat dan sembuh dari penyakitnya. Sedangkan dalam hal persalinan terapi cermin mampu menunjukkan keadaan sesungguhnya posisi bayi secara visual pada ibu yang sedang melakukan persalinan yang berdampak tumbuhnya motivasi ibu dalam melakukan usahanya untuk mengejan dan mengesampingkan rasa nyerinya. Metode penelitian : Pengukuran nyeri dilakukan terhadap 20 ibu bersalin kala II, pada saat ibu diajari mengejan 5 kali ibu tidak dapat melakukan mengejan dengan benar lalu dilakukan penilaian skala nyeri setelah itu dilakukan perlakuan terapi cermin dengan diletakkannya cermin dengan panjang dan lebar $10 \mathrm{~cm}$. Setelah itu memimpin ibu untuk melihat keadaan bayinya sampai ibu menemukan titik konsentrasinya dan akan mencapai konsentrasi yang sangat tinggi dan pikiran ibu dipengaruhi oleh gambaran dari cermin sehingga ibu memiliki sugesti yang sangat kuat.

Hasil sebelum diberikan terapi cermin adalah 18 responden (90\%) dengan tingkat nyeri berat, sedangkan nyeri sedang hanya 2 responden (10\%). Setelah diberikan terapi cermin nyeri sedang ada 16 responden (20\%), sedangkan nyeri berat sejumlah 4 responden (20\%). Data yang diperoleh dianalisis secara statistik dengan uji T Paired t-Test menggunakan SPSS. Pemberian terapi cermin terbukti efektif dalam menurunkan nyeri persalinan pada kala II.

\section{Kata kunci : Cermin, Intensitas Nyeri, persalinan}

\section{PENDAHULUAN}

Seorang wanita, dalam kehidupannya akan mengalami tahapan-tahapan reproduktif. mulai dari menstruasi, hamil, melahirkan, sampai tahap menopause. Salah satu proses yang dialami seorang wanita adalah proses persalinan. Proses persalinan atau melahirkan seorang anak adalah hal yang alami bagi seorang wanita yang memang sudah dirancang untuk tujuan tersebut. (Bobak, 2004)

Proses persalinan adalah suatu hal yang fisiologis. Karena, dalam proses persalinan ibu akan mengalami beberapa tahapan persalinan yang terjadi secara alami. dimulai dari distensi uterus, peregangan serviks, sampai penurunan kepala janin. Karena tahapan proses persalinan tersebut ibu bersalin akan merasakan nyeri yang berlangsung terus-menerus dan semakin kuat. (Tamsuri, 2006)

Tidak dipungkiri, persalinan itu sendiri merupakan tugas berat yang harus dilakukan oleh seorang ibu hamil. Diperlukan segenap tenaga dan pikiran untuk melaksanakannya. Rasa sakit, rasa lelah, tegang dan hal lainnya membayangi proses persalinan yang dihadapi. Banyak Ibu hamil merasakan bahwa, persalinan merupakan proses yang cukup menakutkan untuk dilalui. Namun, ada juga ibu hamil yang mengatakan bahwa proses melahirkan adalah merupakan kodrat wanita yang mudah untuk dilalui.

Saat ini banyak peneliti yang menemukan metode terapi yang dapat mengurangi rasa nyeri dengan bantuan alat cermin. Salah satu peneliti dari University of California mengungkapkan cermin bisa digunakan untuk meringankan nyeri sendi (arthritis). Terapi ilusi optik ini ternyata bisa membantu pasien arthritis (McCabe, 2011).

Terapi cermin ini adalah kekuatan penglihatan. Dalam kasus ini, penglihatan mengesampingkan apa yang dianggap sebagai sensasi terkuat, yaitu rasa sakit. Terapi ini tampaknya dapat digunakan sebagai cara untuk mengurangi rasa sakit, seolah-olah otak pasien dapat memperkirakan kembali sehat dan sembuh dari penyakitnya (McCabe, 2011). 
Saat ini di kala muncul kesadaran akan back to nature dan efek samping dari pemakaian obat kimia sintetis, sebuah media cermin digunakan pada unit persalinan di rumah sakit California. Rumah sakit bersalin di sana pada saat memandu persalinan, dokter dan bidan meletakkan sebuah cermin di dekat lubang vagina yang dapat dengan mudah dilihat oleh sang ibu pada saat masa bersalin. Efeknya, sebagai media terapi cermin meningkatkan dan merangsang hormone oksitosin yang ada di dalam tubuh ibu sehingga kontraksi akan semakin sering disamping memunculkan semangat yang tinggi karena terpengaruhnya ibu terhadap gambar dicermin. Sehingga, tidak menimbulkan rasa takut pada ibu-ibu yang akan melahirkan melainkan Ibu lebih bersemangat melawan rasa sakit agar bayinya segera lahir (Gaskin, 2003).

\section{METODE PENELITIAN}

Desain yang digunakan dalam penelitian ini adalah analitik pre eksperimental dengan pre test - posttest design. Penelitian ini dilakukan dengan cara melakukan pengamatan awal (pre test) terlebih dahulu sebelum diberikan intervensi, setelah itu diberikan intervensi, kemudian dilakukan pengamatan terakhir (posttest) (Hidayat, 2007).

Populasi dalam penelitian ini adalah 20 ibu bersalin kala II dengan persalinan normal yang mengalami nyeri persalinan di BPS Ny. Roudlotul Nasikha Ngemplakrejo Kota Pasuruan.

HASIL

Frekuensi nyeri sebelum perlakuan terapi cermin.

Tabel 1. Distribusi responden sebelum dilakukan tindakan dengan skala Vds

\begin{tabular}{ccccccc}
\hline Tingkat Nyeri & \multicolumn{3}{c}{ Kategori } & \multicolumn{3}{c}{ Total } \\
\hline & $\begin{array}{c}\text { Tidak } \\
\text { Nyeri }\end{array}$ & $\begin{array}{c}\text { Nyeri } \\
\text { Ringan }\end{array}$ & $\begin{array}{c}\text { Nyeri } \\
\text { Sedang }\end{array}$ & $\begin{array}{c}\text { Nyeri } \\
\text { Berat }\end{array}$ & $\begin{array}{c}\text { Nyeri Tak } \\
\text { Tertahankan }\end{array}$ \\
\hline 0 & 0 & 0 & 0 & 0 & 0 & 0 \\
$1-3$ & 0 & 0 & 0 & 0 & 0 & 0 \\
$4-6$ & 0 & 0 & 2 & 0 & 0 & 18 \\
$7-9$ & 0 & 0 & 0 & 18 & 0 & 0 \\
10 & 0 & 0 & 0 & 0 & 0 & 0 \\
\hline Jumlah & 0 & 0 & 2 & 18 & $0 \%$ & $100 \%$ \\
\hline
\end{tabular}

Sumber : data primer yang diolah (2012)

Dari data diatas dapat dilihat bahwa responden dengan tingkat nyeri yang paling banyak adalah nyeri berat dengan jumlah 18

responden $(90 \%)$, sedangkan nyeri sedang hanya 2 responden (10\%).

Frekuensi nyeri setelah perlakuan terapi cermin

Tabel 2. Distribusi responden setelah dilakukan tindakan dengan skala Vds

\begin{tabular}{|c|c|c|c|c|c|c|}
\hline \multirow{2}{*}{$\begin{array}{l}\text { Tingkat } \\
\text { Nyeri } \\
\end{array}$} & \multicolumn{3}{|c|}{ Kategori } & \multicolumn{3}{|c|}{ Total } \\
\hline & $\begin{array}{l}\text { Tidak } \\
\text { Nyeri }\end{array}$ & $\begin{array}{l}\text { Nyeri } \\
\text { Ringan }\end{array}$ & $\begin{array}{l}\text { Nyeri } \\
\text { Sedang }\end{array}$ & $\begin{array}{r}\text { Nyeri } \\
\text { Berat }\end{array}$ & $\begin{array}{c}\text { Nyeri Tak } \\
\text { Tertahankan }\end{array}$ & \\
\hline 0 & 0 & 0 & 0 & 0 & 0 & 0 \\
\hline $1-3$ & 0 & 0 & 0 & 0 & 0 & 0 \\
\hline $4-6$ & 0 & 0 & 16 & 0 & 0 & 16 \\
\hline 7-9 & 0 & 0 & 0 & 4 & 0 & 4 \\
\hline 10 & 0 & 0 & 0 & 0 & 0 & 0 \\
\hline Jumlah & 0 & 0 & 16 & 4 & 0 & 20 \\
\hline Presentase & $0 \%$ & $0 \%$ & $80 \%$ & $20 \%$ & $0 \%$ & $100 \%$ \\
\hline
\end{tabular}

Sumber : data primer yang diolah (2012) 
Dari data diatas dapat dilihat bahwa skor responden dengan nyeri sedang ada 16 responden $(20 \%)$, sedangkan nyeri berat sejumlah 4 responden (20\%).

Penurunan nyeri persalinan kala II sebelum dan setelah perlakuan terapi cermin

Tabel 3. Distribusi frekuensi nyeri sebelum dan sesudah pemberian terapi cermin terhadap nyeri persalinan kala II

\begin{tabular}{|c|c|c|c|c|c|c|c|c|c|c|c|c|c|}
\hline \multirow[t]{3}{*}{ Tingkat Nyeri } & & & & & & \multirow[t]{3}{*}{ Total } & \multirow{3}{*}{$\begin{array}{l}\text { Tingkat } \\
\text { Nyeri }\end{array}$} & & & & & & \multirow[t]{3}{*}{ Total } \\
\hline & \multicolumn{5}{|c|}{ Kategori Pre Test } & & & \multicolumn{5}{|c|}{ Kategori Pre Test } & \\
\hline & TN & $\mathbf{R}$ & $S$ & B & TT & & & TN & $\mathbf{R}$ & $S$ & B & TT & \\
\hline 0 & 0 & 0 & 0 & 0 & 0 & 0 & 0 & 0 & 0 & 0 & 0 & 0 & 0 \\
\hline $1-3$ & 0 & 0 & 0 & 0 & 0 & 0 & $1-3$ & 0 & 0 & 0 & 0 & 0 & 0 \\
\hline $4-6$ & 0 & 0 & 2 & 0 & 0 & 2 & $4-6$ & 0 & 0 & 16 & 0 & 0 & 16 \\
\hline $7-9$ & 0 & 0 & 0 & 18 & 0 & 18 & $7-9$ & 0 & 0 & 0 & 4 & 0 & 4 \\
\hline 10 & 0 & 0 & 0 & 0 & 0 & 0 & 10 & 0 & 0 & 0 & 0 & 0 & 0 \\
\hline Jumlah & 0 & 0 & 2 & 18 & 0 & 20 & & 0 & 0 & 16 & 4 & 0 & 20 \\
\hline Persentase(\%) & 0 & 0 & 10 & 90 & 0 & 100 & & 0 & 0 & 80 & 20 & 0 & 100 \\
\hline
\end{tabular}

Berdasarkan hasil uji paired T-test menunjukkan $\mathrm{t}$ hitung sebesar 6,658 dan $\mathrm{t}$ table sebesar 2,101 pada tingkat kepercayaan 95\% didapatkan nilai sig $(0,000)<\alpha=0,05$ maka $\mathrm{H}_{0}$ ditolak, yang artinya ada perbedaan intensitas nyeri sebelum dilakukan perlakuan dan setelah diberikan perlakuan. maka $\mathrm{H}_{1}$ diterima artinya ada pengaruh pemberian terapi cermin terhadap penurunan nyeri persalinan kala II.

\section{PEMBAHASAN}

Tingkat Nyeri Kala II pada Ibu sebelum diberikan perlakuan terapi cermin.

Dari hasil penelitian ini didapatkan pada tabel 1. diketahui bahwa responden sebelum diberikan perlakuan terapi cermin didapatkan hasil tingkat nyeri kala II nyeri sedang 2 orang (10\%), hal ini secara subyektif dapat diamati yaitu ibu mendesis, menyeringai, dapat menunjukkan lokasi nyeri dengan tepat dan dapat mengatakan rasa nyerinya, masih dapat mengikuti perintah terhadap tindakan manual. Sebagian besar nyeri berat 18 orang (90\%) yang secara subyektif dapat diamati secara langsung yaitu ibu terkadang tidak dapat mengikuti perintah tetapi masih dapat merespon
Data yang didapat dari 20 ibu bersalin sebelum dan sesudah perlakuan cermin dengan penurunan intensitas nyeri pada kala II tindakan yang diberikan oleh bidan, dapat menunjukkan lokasi nyeri tetapi tidak dapat menceritakan rasa nyerinya, tidak dapat diatasi dengan nafas panjang dan alih posisi. Hal ini dapat saja terjadi karena responden tidak mengerti bahkan tidak tahu bagaimana cara mengkompensasi rasa nyeri pada saat menjelang persalinannya

Tingkat Nyeri Kala II pada Ibu yang diberikan perlakuan terapi cermin.

Dari hasil penelitian ini didapatkan pada tabel 2. diketahui bahwa ibu bersalin yang diberikan perlakuan terapi cermin yaitu pada saat pengambilan data, dari 20 responden yang tingkat nyeri sedang tedapat 16 orang $(80 \%)$ secara subyektif ibu dapat berkomunikasi dengan baik dan jelas.

Sedangkan responden yang mengalami nyeri berat terdapat 4 orang $(20 \%)$ secara subyektif ibu mendesis, sesekali menyeringai, dapat menunjukkan lokasi nyeri dengan tepat dan dapat mengatakan rasa nyerinya, ibu dapat mengikuti perintah dengan baik dan respon terhadap tindakan manual.

Tidak ada responden yang mengalami nyeri berat dan nyeri tidak tertahankan. 
Pendapat Danang (2008), persepsi nyeri mencakup proses sensasi ketika stimulus nyeri terjadi dan berhubungan dengan interpretasi nyeri oleh seseorang dengan ambang nyeri. Adaptasi setiap orang tidaklah sama sehingga memungkinkan terjadinya perbedaan ambang nyeri pada setiap orang karena adanya perubahan sesuai dengan adaptasi yang dialami. Nyeri pada dasarnya adalah personal experience pengalaman seorang individu. Jadi dengan demikian persepsi nyeri itu sangat individual dan unik pada setiap orang baik itu durasi, berat atau intensitas, periode dari nyeri. Nyeri itu adalah perasaan campuran dan terjadi pada berbagai tingkatan. Pernyataan ini juga didukung oleh Tamsuri (2006), bahwa pada saat terjadi nyeri banyak perilaku yang diungkapkan oleh seorang klien yang mengalami nyeri seperti menangis, meringis, meringkukkan badan, menjerit dan perilaku klien dalam menghadapi nyeri ini dapat dipengaruhi oleh kemampuan tubuh dalam menoleransi nyeri.

Sebagian besar responden berusia 2130 tahun terdapat 10 orang (50\%), usia kurang dari 20 tahun tedapat 4 responden $(20 \%)$, sedangkan responden berusia lebih dari 31-40 tahun terdapat 6 responden (30\%). Hal ini menunjukkan bahwa ibu bersalin yang diberikan perlakuan terapi cermin saat kehamilannya tersebut sangat bervariasi jika dihubungkan dengan nyeri persalinan kala II sesuai dengan teori. Pendapat Ramadhan (2001), Orang dewasa tua mengalami perubahan neurofisiologi dan mungkin mengalami penurunan persepsi sensori, stimulus serta peningkatan ambang nyeri. Namun nyeri persalinan terutama kala II dapat diminimalisir dengan diberikan terapi cermin.

\section{Pemberian terapi cermin dalam penurunan} intensitas nyeri persalinan kala II

Hasil penelitian menunjukkan adanya pengaruh pemberian terapi cermin terhadap intensitas nyeri pada ibu inpartu kala II, dimana 20 responden yang diberikan perlakuan dengan terapi cermin pada saat persalinannya tingkat nyeri yang paling banyak adalah nyeri sedang $80 \%$ dan nyeri berat $20 \%$. Sedangkan sebelum diberikan perlakuan terapi cermin pada saat persalinannya tingkat nyeri yang paling banyak adalah nyeri berat yaitu 90\% dan nyeri sedang hanya $10 \%$. Ibu bersalin yang diberikan perlakuan terapi cermin dapat melakukan konsentrasi yang sangat tinggi dari pengaruh gambaran dari cermin sehingga ibu lebih focus, tenang, rileks dan ketegangan otot dapat dikurangi sehingga nyeri persalinan kala II dapat diminimalisir (Gaskin, 2003).

Menurut McCabe (2011), terapi ini adalah kekuatan penglihatan. Dalam kasus ini penglihatan mengesampingkan apa yang dianggap sebagai sensasi terkuat, yaitu rasa sakit. Terapi ini tampaknya dapat digunakan sebagai cara untuk mengurangi rasa sakit, seolah-olah otak pasien dapat memperkirakan kembali sehat dan sembuh dari penyakitnya.

Menurut Gaskin (2003), sebagai media visualisasi bantuan dari cermin secara tidak sengaja ibu memperhatikan gambar yang diperlihatkan dari cermin pikiran ibu akan dipengaruhi dari gambaran tersebut sehingga ibu memiliki sugesti yang sangat kuat dan perhatian ibu lebih terpusat dan lebih focus dan ibu mencapai konsentrasi yang sangat tinggi.

\section{KESIMPULAN}

Pemberian terapi cermin terbukti efektif dalam menurunkan nyeri persalinan pada kala II.

\section{DAFTAR PUSTAKA}

Barbara, Kozier, Glenoro, Rita Oliveri, 2006. Fundamental Of Nursing, California: Adisson Wesley Publishing Company Ine

Bobak, Lowdermik, Jensen, 2004. Keperawatan Maternitas, Jakarta : EGC 
Budiarto, E, 2004, Metode Penelitian Kedokteran, Jakarta EGC

Danuatmaja, B dan Meiliasari, M, 2004, Persalinan Normal Tanpa Rasa Sakit, Jakarta : EGC

Gaskin, 2003, Panduan Untuk Kelahiran Bayi, http ://www. bidankita. com/index. php?option $=$ com content\&view $=$ article\&id=268\&Itemi $\mathrm{d}=1$

Henderson, C. 2005. Buku Ajar Konsep Kebidanan. Jakarta. EGC

Hidayat, A, Aziz Alimul, 2007. Metode Penelitian dan Teknik Analisa Data, Jakarta : Salemba Medika

Manuaba, Ida Bagus, 1998, Ilmu Kebidanan Penyakit Kandungan dan Keluarga Berencana Untuk Pendidikan Bidan, Jakarta EGC

McCabe, 20011, Terapi Cermin, http://health.ghiboo.com/benarkahcermin-bantu-sembuhkan-nyerisendi

Mender, R. 2003. Nyeri Persalinan. Jakarta. EGC

Muchtar, Rustam, 1998, Sinopsis Obstetri, Jilid 1 Edisi 2, Jakarta EGC

Munandar, 2011, Ilmu Alamiah Dasar Penemu dan Sejarah Cermin, http://www.berbagaihal.com//2011/0 6/sejarah-penemuan-cermin.html

Notoatmodjo, Sukidjo, 2002, Metodologi Penelitan Kesehatan, Jakarta, Rineka Cipta.

Nursalam, Pariani. S. 2001. Pendekatan Praktis Metodologi Riset Keperawatan. Jakarta. Salemba Medika

Prof. DR. Sugiyono. 2005. Statistika Untuk Penelitian. Bandung. IKAPI. CV. ALFABETA

Sarwono Prawirohardjo (2002). Ilmu Kebidanan. Jakarta, YBP-SP

Simkin, P dan Ancheta, R, 2005, Buku Saku Persalinan, Jakarta : EGC 